\title{
‘Amerikan Güzeli’ Filminin Akılcı Duygusal Davranışçı Terapi ve Bilişsel Terapi’nin Bazı Kavram ve Görüşleri Açısından İncelenmesi
}

\section{Analysis of 'American Beauty' Movie in terms of Rational Emotional Behavioral Therapy and Some Concepts and Views of Cognitive Therapy}

\begin{abstract}
Yelda YILDIZ*
Öz: Bu çalışmada, 1999 yılında Sam Mendes yönetmenliğinde çekilen Amerikan Güzeli (American Beauty) filminin ana karakterleri Lester Burnham, Carolyn Burnham, Jane Burnham ve Albay Frank Fitts'in genel davranışları ve önemli görülen söylemleri Akılcı Duygusal Davranışçı Terapi ve Bilişsel Terapi’nin bazı kavram ve görüşleri açısından incelenmiştir. Bu çalışma betimsel bir çalışma olup, yöntem olarak doküman analizi kullanılmıştır. Sonuç olarak, bu kişilerin mantıksız inanç, düşünce ve davranışlarının fazlalılı̆̆ı nedeniyle bireysel, aile ve toplumsal yaşantılarının olumsuz etkilendiği görülmüştür. Her iki ekol açısından bakıldığında, tüm karakterlerin mantıksızlığa yatkınlıkları aile bireyleri, arkadaşları, kitle iletişim araçları ve içinde yaşadıkları toplum tarafından beslenmiştir. Ruh sağlığı alanında eğitim alan ve çalışan bireylere her iki ekolün kuramsal öneminin fark ettirilmesi, derinlemesine bir anlatımının yapılabilmesi için bu çalışmada olduğu gibi film analizi yönteminin kullanılmasının ve insanların gerçek dünyalarına, kimlik arayışlarına, anlamsızlığa, yabancılaşmaya, ruhsal sorunlara odaklanan filmlerin psikolojik analizlerinin yapılmasının alana önemli katkılar sağlayacağ düşünülmektedir.

Anahtar Kelimeler: Akılcı duygusal davranışçı terapi, bilişsel terapi, film analizi, doküman analizi, akılcı olmayan inançlar, mantıksız düşünceler
\end{abstract}

\begin{abstract}
In this study, the main characters of American Beauty movie directed by Sam Mendes in 1999, Lester Burnham, Carolyn Burnham, Jane Burnham and Colonel Frank Fitts's general behaviors and important discourses are examined in terms of the basic concepts and views of both Rational Emotional Behavioral Therapy and Cognitive Therapy. This study is a descriptive study and document analysis is used as a method. As a result, it was seen that individual, family and social lives of these people were negatively affected due to the excess of their illogical beliefs, thoughts and behaviors. Tendency of illogicality of all characters has been fed by family members, friends, the society in which they live and mass media. It is recommended to use movie and working in the field of mental health. At the same time, it is thought that psychological analysis of movies focusing on people's real worlds, seeking identity, meaninglessness, alienation, and psychological problems will make significant contributions to the field.
\end{abstract}

Keywords: Rational emotive behavioral therapy, cognitive therapy, film analysis, document analysis, irrational beliefs, illogical thoughts

\section{Giriş}

Sanat, insan doğasının farklı ortamlarda gözlenmesini ve analiz edilmesini sağlar. Bir sanat dalı olan sinema aracılı̆̆ıyla farklı zaman ve çevrelerdeki insanlar hakkında sosyal, antropolojik ve kültürel bilgi edinilir. Bu yolla insan hayatının yorumlanması ve anlaşılması kolaylaşır (Marcus, 1999). Sanatçının bakış açısını açıklamak için belirli bir estetik kullanılması noktasında, ruh sağlığı eğitiminde de sinema bir araç olarak kullanılır (Quadrelli, Colt ve Semeniuk, 2009). İyi bir film, yaşanmış bir psikolojik rahatsızlığın üç boyutlu gerçek niteliğini ve rahatsızlığın öncül olan ayırt edici özelliklerini verebilir. Bu arada gerçek insanları, onların hayatlarını, kişisel davranış kalıplarını, yaşadıkları zorlukları, umutlarını ve başa çıkma yöntemlerini gösterebilir (Richards, 2016). Sinema, terapötik bir müdahale aracı olarak kullanıldığında; danışanlara yaşadıkları problemle ilgili içgörü kazanabilecekleri, hayatlarında pozitif kurallar geliştirebilecekleri ve model alabilecekleri yararlı davranışları içeren filmler ev ödevi olarak

\footnotetext{
* Dr. Öğr. Üyesi, Medipol Üniversitesi, Eğitim Fakültesi, İstanbul-Türkiye, ORCID: 0000-0002-2397-4778, e-posta: yeldayildiz@medipol.edu.tr.
} 
verilir (Mangot ve Murphy, 2017) ya da film danışanla birlikte izlendikten sonra filmle ilgili danışanın duygu ve düşünceleri irdelenir (Berg-Cross, Jennings ve Baruch, 1990). Böylece danışanların uzun süreli empati ve yansıtıcı düşünce geliştirmelerine yardımcı olunur (Preminger, 2012). Sinema sadece danışanların ve toplumun gelişimi için değil aynı zamanda medikal/psikiyatri ve psikoloji eğitimi alan bireylerin, bireysel ve grup çalışmalarıyla, psikolojik sağlık ve rahatsızlıklarla ilgili bilgilerini arttırmak ve terapötik becerilerini geliştirmek için kullanılır (Gramaglia, Jona, Imperatori, Torre ve Zeppegno, 2013). Eğitsel amaçlı kullanılan filmler arasında; psikopatoloji ile bağlantılı filmler; ruh sağlığı eğitimi alan öğrencilerin izlemesi gerektiğine inanılan filmler; psikopatolojiyle doğrudan bağlantılı olmayan kışkırtıcı, etkileyici ve çeşitli psikolojik fenomenler için örnek oluşturan, karakter gücünü, direncini ve değişik psikolojik durumları tasvir eden filmler yer almaktadır (Wedding ve Niemiec, 2016).

Ruh sağlığı alanında konuyla ilgili yapılan çalışmalara bakıldığında; sinemanın ruh sağlığı eğitiminde ve terapideki kullanımının ele alındığ (Gramaglia ve diğerleri, 2013; Klemenc-Ketis ve Kersnic, 2011; Mangot ve Murphy, 2017; Sanchez, Gutierrez ve Morales, 2010; Wedding ve Niemiec, 2016), alkolizmle ilgili inançları ve temaları içeren The Country Girl filminin yorumlayıcı okumasının yapıldığı (Basic, 1992); mükemmeliyetçilik ve ilişkili şemalarda sinema terapinin etkisinin incelendiği (Türküler-Aka ve Gençöz, 2010); farklı terapi ekolleri bağlamında film analizlerinin yapıldığ (Acar ve Voltan-Acar, 2013; Boyac1 ve İlhan, 2016; Bozda $\breve{g}$, 2018; Cag ve Voltan-Acar, 2015; Hewison, 2003; Mert ve Soyer, 2014; Morsünbül, 2015; Peoples ve Helsel, 2013; Şenol-Durak ve Fışıloğlu, 2007; ÜlkerTümlü ve Voltan-Acar, 2014); Benim Çocuğum filmi aracılığıyla psikolojik danışman eğitiminde cinsel yönelim olgusunun irdelendiği (Kağnıc1, 2015) görülmüştür. Ancak bilişsel ekollerin, duyguların, düşüncelerin ve davranışların döngüsel bir nedensellik içerisinde birbirini etkilediği (Burns, 2008), psikolojik sorunların genelde bilişsel süreçlerdeki zorluklardan kaynaklandığı ve düşünce, duygu, davranış değişiminin oluşması için bilişsel sürece odaklanılması gerekliliği görüşü (Arnkoff ve Glass, 1992; Corey, 2008; Dobson ve Block, 1988; Weishaar, 1993) çarpıcı sahneleriyle Amerikan Güzeli (American Beauty) filminde gözler önüne serilmesine rağmen filmin bu ekoller bağlamında psikolojik analizinin yapılmaması alanda bir eksiklik olarak görülmüştür. Dolayısıyla bu çalışmada Amerikan Güzeli filminin bilişsel ekollerden Albert Ellis'in Akılcı Duygusal Davranış̧̧ı Terapi (ADDT) ve Aaron Beck'in Bilişsel Terapi (BT) ekollerinde yer alan bazı kavram ve görüşlerle analiz edilmesi, böylelikle ruh sağlığı eğitimi alanların ve alan çalışanlarının kuramsal bilgilerini güçlendirmeleri amaçlanmıştır. Bu doğrultuda öncelikli olarak ADDT ve BT yaklaşımları kısaca açıklanmış ardından bu yaklaşımların bazı kavram ve görüşleriyle açıklanabilecek Amerikan Güzeli filminin ana karakterlerinin önemli görülen davranışları ve söylemleri analiz edilmiştir. Yapılan analizlerde, ADDT'nin akılcı olmayan inanç, durağanlı̆̆a karşı gelme eğilimi, mükemmelliyetçilik, kendini/diğerlerini/içinde yaşadiğı dünyayı kabul kavramları, A-B-C modeli ve ADDT'nin oluşumunda yararlanılan hedonizm, rasyonalizm yaklaşımlarıyla birlikte BT'nin temel inançlar, danışanın kendisini, çevresini ve geleceğini olumsuz değerlendirdiği bilişsel üçlü ve ya hep ya hiç düşüncesi, aşırl genelleme, zihinsel filtre, olumluyu geçersiz kılmak, felaketleştirme, aşırı büyütme ya da küçültme, duygusal kararlar, meli-malı cümleler, etiketleme'nin yer aldığı bilişsel hatalar/mantıksız düşünceler kavramları kullanılmıştır. Aynı zamanda, mantıksız inanç ve düşüncelerin oluşumuna etki eden faktörler de her iki yaklaşım doğrultusunda ele alınmıştır.

\begin{abstract}
Akılcı Duygusal Davranışçı Terapi Yaklaşımı
ADDT, güçlü felsefi temelleri olan ve yaşama bakış açısında anlamlı değişiklikler yapılmasını hedefleyen psikoterapi biçimidir (Köroğlu, 2008). Ellis ADDT’yi oluştururken felsefe, hedonizm, hümanizm, rasyonalizm gibi birçok yaklaşım ve görüşten etkilenmiştir (Sharf, 2000). Ellis, düşünce, duygu ve davranışların etkileşim halinde olduğunu ve birçok duygusal problemde, kişinin kendi kendine olumsuz konuşmasının (-meli, -malı gibi) ve akılcı olmayan düşüncelerin ('mükemmel olmalıyım' gibi) rolü olduğunu belirtmektedir (Burns, 2008). İnsanların yaratma ve kendini gerçekleştirme potansiyeli olmasına rağmen hedeflerine uymayan, olumsuz sonuçlara yol açan düşünme potansiyeli de vardır (Clark, 2000; Ellis, 1994). İnsanların hem mantıklı hem mantıksız olma eğilimleri varken sorumsuz insanlar mantıksız ve akılcı olmayan bir şekilde davranmaktadır (Nelson-Jones, 1982). Bu durum başarısızlığa, katılığa, zorunluluğa, durağanlığa neden olmakta ve yoğun duygusal veya soğuk duygular ortaya çıkarmaktadır (Ellis ve Harper, 2005). Açıklıktan, esneklikten ve pragmatik olmaktan yana olan ADDT'nin temel varsayımına göre, insanların olayları ve yaşantıları değerlendirme biçimleri psikolojik güçlükleri belirlemektedir (Ellis ve Harper, 2005). Dolayısıyla duygulanımın kaynağı, inançlar,
\end{abstract}


yorumlar ve yaşantılara verilen tepkilerdir (Corey, 2008). İnsanların mantıksızlığa yatkınlıkları çevreleri tarafından özellikle ilk çocukluk döneminde beslenmektedir (Nelson-Jones, 1982). Akılcı olan ve olmayan inançlar, aile bireylerinden, akranlardan, öğretmenlerden, toplumdan ve kitle iletişim araçlarından öğrenilmektedir (Clark, 2000; Hackney ve Cornier, 2008).

Ellis, insanların içsel konuşmaları nedeniyle kendilerine sürekli değer atfinda bulunduğunu ve kendilerini etiketlediğini belirmektedir. Dolayısıyla çoğu rahatsızlığın temelinde kişinin kendini suçlamasının yani kendini kabul etmemesinin olduğunu savunmaktadır. Ellis'e göre sevme, onaylanma, başarı arzusu gibi temel tercihlerle ihtiyaçların birbirine karışması, duygusal ve davranışsal problemlere yol açmaktadır (Corey, 2008). Ellis, duygusal rahatsızlığı olan insanların kendilerine, başkalarına ve dünyaya ilişkin talepleri bakımından üç temel mantıksız inanç ileri sürmüştür. Bunlar: 'İyisini yapmalıyım ve tüm başarılarım takdir edilmeli, aksi halde başarısız birisi olacağım.'; 'Bana karşı nazik, düşünceli ve adaletli olmalısın, aksi halde işe yaramaz birisi olacağım.'; 'Yaşama koşullarım iyi ve rahat olmalı, böylece istediğim her şeyi çok fazla çaba sarf etmeden ve rahatsızlık duymadan elde edebilmeliyim aksi takdirde bu lanet bir dünyadır ve hayat yaşamaya değmez' (Nelson-Jones, 1982, s. 52). ADDT, duygusal rahatsızlığı asgari düzeye indirmek için bireylerin kendilerini, diğerlerini, içinde yaşadıkları dünyayı koşulsuz kabul etmelerine ve daha hoşgörülü olmalarına yardımcı olmaktadır (Ellis, 2004)

Temel amacı mantıksız inançları değiştirmek olan ADDT, A-B-C modelini uygulamalarının merkezine koymuştur. A; tetikleyici bir olay veya bir kişinin davranışıdır. C; bireyin duygusal, bilişsel veya davranışsal sonuçlarıdır. C'nin oluşumunda etkili olan süreç kişinin A hakkındaki inancı olan B'dir. C'den sonra gelen D, terapötik süreçte danışanların akılcı olmayan söz konusu inançlarının tartışılmasıdır. Bununla birlikte danışanlar etkili davranış biçimi olan E'ye ulaşırlar (Hackney ve Cornier, 2008).

\section{Bilişsel Terapi Yaklaşımı}

Aaron T. Beck, depresyonla ilgili yaptığı klinik gözlemler ve çalışmalar sonucunda BT yaklaşımını geliştirmiştir. Beck, depresif danışanların düşünsel karmaşa yaşamaları nedeniyle hayat olayları karşısında nesnel olmadıklarını ve olumsuz bir yaklaşıma sahip olduklarını belirtmiştir (Beck, Rush, Shaw ve Emery, 1987). Beck, mantık dışı inançlar yerine bazı görüşlerin aşırı kesin, geniş ve sıra dış1 olduğunu savunur. Ona göre, insanlar kurallarla (önermeler veya formüller) yaşarlar; birtakım gerçekdışı kurallarla etiketleme, yorumlama ve değerlendirme yaptıklarında veya kuralları uygunsuzca veya aşırı kullandıklarında sıkıntıya düşerler (Corey, 2008, s. 315). Beck (2006), bilişsel yapıyı üç bölümle açıklamıştır. Bunlar; otomatik düşünceler, ara inançlar ve temel inançlardır. Otomatik düşünceler görünür olmasına rağmen temel inançlar derindedir, ara inançlar ise ikisinin ortasındadır. Sevilemezlik inancı ve çaresizlik inancı olumsuz temel inançlardır. Olumsuz temel inançlar genellikle, evrensel, genelleyici ve değişime dirençlidir. Temel bir inanç harekete geçtiğinde, bireyin o inanc1 destekleyecek kanıtları bulması daha kolay olup inanca ters olan veriler genellikle çarpıtılır (Beck, 2001).

Beck, depresyonun psikolojik yapısını açıklamak için de üç kavram ileri sürmüştür. Bunlar; bilişsel üçlü, şemalar ve bilişsel hatalardır (mantıksız düşünceler). Bilişsel üçlünün ilk örüntüsünde, danışan kendisini değersiz ve kusurlu bulduğu için kendisini sürekli eleştirme eğilimindedir. İkinci örüntüde, danışan çevreyi olumsuz bir şekilde yapılandırdığı için deneyimlerini de olumsuz yorumlamaktadır. Üçüncü örüntüde danışan şimdi yaşadığı problemlerin aralıksız devam edeceğine inanmaktadır (Beck, Rush, Shaw ve Emery, 1987).

Beck'in ileri sürdügü kavramlardan şemalar, uyarımları ayrıştıran, kodlayan ve kişinin kendisiyle ilgili tartışmasız kabul ettiği bilişsel yapılar olarak açıklanmaktadır. Depresyon modelinin son kavramı olan bilişsel hatalar ise kişilerin yanlış çıkarımlarda bulunmalarına ve yanlış anlamalarına neden olan mantıksız düşüncelerdir. Bunlar; ya hep ya hiç düşüncesi, aşırı genelleme, zihinsel filtre, olumluyu geçersiz kılmak, aşırı büyütmeya da küçültme, duygusal kararlar, felaketleştirme, meli-malı cümleler, etiketleme ve kişiselleştirme'dir (Burns, 2008). Beck'in kuramı, danışanların olumsuz düşüncelerini, uyumsuz inançlarını tanımaya ve değiştirmeye odaklıdır. Danışanların iç görü kazanmaları hedeflenmektedir (Arkar, 1992; Corey, 2008). ADDT ve BT hakkında yapılan özet açıklamalardan sonra bu araştırmada ADDT ve BT'nin bazı kavram ve görüşleriyle açıklanabilecek Amerikan Güzeli filminin ana karakterlerinin önemli görülen davranışları ve söylemleri analiz edilmiştir. 


\section{Yöntem}

Bu çalışma, Amerikan Güzeli filminin ADDT ve BT'nin bazı kavram ve görüşleriyle analiz edildiği betimsel bir çalışmadır. Nitel araştırma yöntemlerinden olan doküman incelemesi çalışmada kullanılmıştır. Doküman incelemesi, araştırılması hedeflenen olgu/olgular hakkında bilgi içeren yazılı kaynakların ve film, video, fotoğraf gibi görsel kaynakların analizini kapsar (Yıldırım ve Şimşek, 2008). Doküman analizi, araştııılan konuyla ilgili detaylı veri toplanmasını sağlamaktadır (Boyacı ve İlhan, 2016; Goodson ve Walker, 1988).

\section{İşlem}

Sam Mendes yönetmenliğinde çekilen, Burnham ailesininkaramsarlığını ve dağılmasını ele alan Amerikan Güzeli filminin ana karakterleri Lester Burnham (baba), Carolyn Burnham (anne), Jane Burnham (çocuk) ve Albay Frank Fitts'in (Burnham ailesinin komşusu) genel davranışları ve önemli görülen söylemleri incelenmiştir. Bu amaçla öncelikli olarak araştırmacı önemli bir detayı atlamamak için filmi 4 kere izlemiş daha sonraADDT'nin akılcı olmayan inançlar, durağanlı̆̆a karşs gelme eğilimi, mükemmelliyetçilik, kendini/diğerlerini/içinde yaşadı̆̆ dünyayı kabul kavramları, A-B-C modeli ve ADDT'nin oluşumunda yararlanılan hedonizm, rasyonalizm yaklaşımlarıyla birlikte BT'nin temel inançlar, bilişsel üçlü ve bilişsel hatalar/mantıksız düşünceler kavramlarıyla analiz edilebileceği düşünülen genel davranışların ve söylemlerin deşifresini yapmıştır. Deşifresi yapılan her bir davranışın ve söylemin ekoller bağlamında hangi kavramla/kavramlarla veya görüşle açıklanabileceği değerlendirilmiş ve uygun görülen biçimde analizleri yapılmıştır. Okuyucuların kafa karışıklığı yaşamaması için tablolar oluşturulmuş, analiz edilen davranış ve söylemlerin nasıl bir ortamda ortaya çıktığ 1 ve hangi karakterle ilişkili olduğu detaylı bir şekilde açıklanmıştır. Araştırmanın geçerliliği için nitel araştırmada yer alan meslektaş teyidi (Yıldırım ve Şimşek, 2008) yöntemine başvurulmuştur. Nitel araştırma deneyimine güvenilen iki öğretim üyesi ve bir psikolojik danışmandan görüş alınmıştır. Alınan görüşler doğrultusunda analizlerde kullanılan kavram ve yaklaşımlarda bazı değişiklikler yapılmış, bulguların son hali diğer uzmanların da onayı alındıktan sonra tamamlanmıştır. Meslektaş teyidi araştırmanın iç güvenirliğini de etkilemiştir.

\section{Bulgular}

Orijinal adı American Beauty (Amerikan Güzeli) olan ve 2000 yılında vizyona giren ABD yapımı film 5 Oscar ödülü kazanmıştır. Filmde bir Amerikan ailesinin yaşadığı karamsarlık ve dağılma konu edilmiştir. Filmin ana karakterlerinden Lester Burnham (Kevin Spacey) lüks bir banliyöde eşi Carolyn (Annette Bening) ve kızı Jane (Thora Birch) ile yaşamaktadır. Ancak hem eşi hem kızı tarafından saygı duyulmayan Lester, iş hayatının zorlayıcılı̆̆ 1 ve orta yaş bunalımının da etkisiyle yaşamını daha anlamlı kılmak için hayatında birtakım değişiklikler yapar. Emlak işiyle uğraşan Carolyn iş hayatındaki hırsı nedeniyle hayatı kendine ve çevresine karşı zorlaştırırken Jane ise şiddete başvuran bir babası (Albay Frank Fitts-Chris Cooper) olan komşuları Ricky Fitts (Wes Bentley) ile sevgilidir. Her bir aile ferdinin birbirinden kopuk hareket etmesi Burnham ailesinin dağılmasını kaçınılmaz kılmıştır. Filmin demografik bilgileri Tablo 1'de sunulmuştur.

Tablo 1.

Filmle İlgili Demografik Bilgiler

\begin{tabular}{ll}
\hline Yönetmen & Sam Mendes \\
Yapımcilar & Bruce Cohen, Dan Jinks \\
Senarist & Alan Ball \\
Oyuncular & Kevin Spacey, Annette Bening, Thora Birch, Chris Cooper \\
Orijinal Dil & İngilizce \\
Süre & $122 \mathrm{dk}$. \\
Ülke & Amerika Birleşik Devletleri \\
\hline
\end{tabular}

Bu bölümde film karakterlerinin genel özellikleri verilmiş ardından önemli görülen söylemler ve davranışlar ADDT ve BT'nin bazı kavram ve görüşleriyle analiz edilmiştir. Öncelikli olarak, analiz edilen davranışlar Tablo 2'de, söylem analizleri ise Tablo 3'te sunulmuştur. 
‘Amerikan Güzeli’ Filminin Akılcı Duygusal Davranışçı Terapi ve Bilişsel Terapi’nin Bazı Kavram ve Görüşleri Açısından İncelenmesi

Tablo 2.

Analizi Yapılan Davranışlara İlişkin Liste

\begin{tabular}{c|c|l}
\hline Davranış & $\begin{array}{c}\text { Davranışın Kime Ait } \\
\text { Olduğu }\end{array}$ & \multicolumn{1}{c}{ Analizde Kullanılan Kavram veya Görüş } \\
\hline 1 & Lester Burnham & Hedonizm (ADDT) \\
\hline 2 & Lester Burnham & Akılcı Olmayan İnanç (ADDT) \\
\hline 3 & Carolyn Burnham & $\begin{array}{l}\text { Geleceği Değersizleştirme (BT) } \\
\text { Felaketleştirme (BT) } \\
\text { Mantıksı inanç ve düşüncelerin oluşumundaki etkenler } \\
\text { (ADDT ve BT) }\end{array}$ \\
\hline 4 & Jane Burnham & $\begin{array}{l}\text { Etiketleme (BT) } \\
\text { Diğerlerini Kabul (ADDT) }\end{array}$ \\
\hline 5 & Jane Burnham & $\begin{array}{l}\text { Zihinsel Filtre (BT) } \\
\text { Etiketleme (BT) } \\
\text { Mantıksı inanç ve düşüncelerin oluşumundaki etkenler } \\
\text { (ADDT ve BT) }\end{array}$ \\
\hline
\end{tabular}

Tablo 3.

Analizi Yapılan Söylemlere İlişkin Liste

\begin{tabular}{|c|c|c|c|}
\hline Söylem & $\begin{array}{l}\text { Söylemin Kime Ait } \\
\text { Olduğu }\end{array}$ & $\begin{array}{l}\text { Gösterim } \\
\text { Zamanı }\end{array}$ & Analizde Kullanılan Kavram veya Görüş \\
\hline 1 & Lester Burnham & 2. $\mathrm{dk}$. & Durağanlığa Karşı Gelme Eğilimi (ADDT) \\
\hline 2 & Lester Burnham & 3. dk. & $\begin{array}{l}\text { Akılcı Olmayan İnanç (ADDT) } \\
\text { Felaketleştirme (BT) }\end{array}$ \\
\hline 3 & Lester Burnham & 4. dk. & $\begin{array}{l}\text { Kendini Değersizleştirme (BT) } \\
\text { Etiketleme (BT) } \\
\text { Kendini Kabul (ADDT) }\end{array}$ \\
\hline 4 & Lester Burnham & 66. dk. & Rasyonalizm (ADDT) \\
\hline 5 & Lester Burnham & 100. dk. & $\begin{array}{l}\text { Mantıksız inanç ve düşüncelerin oluşumundaki } \\
\text { etkenler (ADDT ve BT) }\end{array}$ \\
\hline 6 & Carolyn Burnham & 11. $\mathrm{dk}$. & $\begin{array}{l}\text { meli-malı cümle (BT) } \\
\text { ABC Modeli (ADDT) }\end{array}$ \\
\hline 7 & Carolyn Burnham & 14. dk. & $\begin{array}{l}\text { Kendini Değersizleştirme } \\
\text { Etiketleme (BT) } \\
\text { Aşırı Genelleme (BT) } \\
\text { Akılcı Olmayan İnanç (ADDT) } \\
\text { Kendini Kabul (ADDT) }\end{array}$ \\
\hline 8 & Carolyn Burnham & 18. $\mathrm{dk}$. & Mükemmelliyetçilik (ADDT) \\
\hline 9 & Carolyn Burnham & 33. dk. & $\begin{array}{l}\text { Aşırı Büyütme ya da Küçültme (BT) } \\
\text { Kendini Değersizleştirme (BT) } \\
\text { Kendini Kabul (ADDT) }\end{array}$ \\
\hline 10 & Carolyn Burnham & 69. dk. & $\begin{array}{l}\text { Çevreyi Değersizleştirme } \\
\text { Aşırı Genelleme (BT) } \\
\text { Felaketleştirme (BT) } \\
\text { Rasyonalizm (ADDT) }\end{array}$ \\
\hline 11 & $\begin{array}{l}\text { Lester Burnham \& } \\
\text { Carolyn Burnham }\end{array}$ & 76. dk. & $\begin{array}{l}\text { meli-malı düşünce (BT) } \\
\text { Olumlu Geçersiz Kılmak (BT) } \\
\text { ABC Modeli (ADDT) }\end{array}$ \\
\hline 12 & Albay Frank Fitts & 25. dk. & $\begin{array}{l}\text { Diğerlerini, Dünyayı Kabul (ADDT) } \\
\text { Felaketleştirme (BT) } \\
\text { Çevreyi Değersizleștirme (BT) } \\
\text { Rasyonalizm (ADDT) }\end{array}$ \\
\hline 13 & Albay Frank Fitts & $\begin{array}{l}\text { 26. dk., 72. dk., } \\
\text { 94. dk.ve 95. dk. }\end{array}$ & $\begin{array}{l}\text { Kendini Kabul (ADDT) } \\
\text { Etiketleme (BT) } \\
\text { meli-malı cümle (BT) } \\
\text { Çaresizlik Temel İnancı (BT) } \\
\text { Sevilemezlik Temel İnancı (BT) }\end{array}$ \\
\hline 14 & Albay Frank Fitts & 73. $\mathrm{dk}$. & $\begin{array}{l}\text { meli-malı cümle (BT) } \\
\text { ABC Modeli (ADDT) }\end{array}$ \\
\hline
\end{tabular}


Karakter 1 - Lester Burnham: Lester, mutlu bir evliliği olmayan, eş ve baba rollerini sağlıklı bir şekilde yerine getirmeyen, eşiyle ve kızıyla iletişim kurmakta başarısız olan, rutin işlerden ve mesleğinden memnun olmayan biridir. Orta yaş dönemi içinde bulunan Lester, bu dönemin gerektirdiği çeşitli yüzleşmelerle karşı karşıya kalmıştır. Bu dönemde kişiler ortaya koydukları ürünlere bağlanma eğilimi taşır. Kişi gerekli verimliliği gösteremediğini düşündüğünde kriz yaşama eğiliminde olur (Ersanlı, 2012). Lester de bu konuda yaşadığ eksiklik nedeniyle telafi arayışına girer. Böyle bir ortamda gençlik tutkularını tekrar yaşamak için kızı Jane'nin arkadaşı Angela'yı cinsel anlamda hedef haline getirir. Angela'yı fiziksel olarak etkilemek için spora başlar, daha basit bir işe başlayıp kendine zaman ayırır ve her zaman istediği spor arabayı alır. Lester'in ADDT'nin savunduğu gerçekçi bir hayatı neden tercih etmediği bazı davranışlarından ve söylemlerinden yola çıkılarak analiz edilmiştir.

Lester: Aslında şimdi bile ölmüş sayılırım. Bana bakın, duş alırken bile mastürbasyon yapıyorum. Günümün en heyecanlı anını bu oluşturuyor. 2. $D k$.

Söylem Analizi (1): Lester'in içsel konuşmalarında kendini ölmüş olarak değerlendirmesi, daha fazla içe kapanmasına, durağanlaşmasına ve potansiyellerini gerçekleştirmekten uzun bir süre kaçınmasına sebep olmuştur. ADDT'nin savunduğu durağanlığa karşı gelme eğilimini göstermediği için sıkıcı olarak değerlendirdiği hayata yönelik çaba sarf edip alternatifler yaratmak yerine (mastürbasyon dişında) yıllarca aynı kısır döngünün içinde yaşamıştır.

Lester: Az sonra tüm olağan felaketler yeniden başlayacak (günlük işlerden bahsediyor). 3. Dk.

Söylem Analizi (2): BT'de yer alan depresyon modelinin son kavramı bilişsel hatalar/mantıksız düşüncelerden felaketleştirme bu cümlede kullanılmıştır. Hemen hemen herkesin günlük olarak yapmas1 gereken işler mevcuttur. Fakat Lester bunları büyüterek hayatı kendine çekilmez kılmıştır. ADDT’ye göe değerlendirildiğinde ise, Ellis'in sunduğu üç temel akılc1 olmayan inançtan biri olan, 'yaşama koşullarım iyi ve rahat olmal, böylece istediğim her şeyi çok fazla çaba sarf etmeden ve rahatsıllı duymadan elde edebilmeliyim, aksi takdirde bu lanet bir dünyadır ve hayat yaşamaya değmez' inanciyla Lester'in var olan durumu felaketleştirdiği söylenebilir.

Lester: Kızımın ve karımın gözünde kaybeden ve utanç verici olarak görülüyorum. Aslında haksız da sayılmazlar. 4. $D k$.

Söylem Analizi (3): BT'ye göre değerlendirildiğinde Beck'in tarif ettiği depresyon modelinin ilk kavramı olan bilişsel üçlüden, kendini değersizleştirme ve depresyon modelinin üçüncü kavramı bilişsel hatalardan (mantıksız düşünce) etiketleme; ADDT'ye göre değerlendirildiğinde ise, kendini kabul etmediği görülmektedir. Lester, hatalarını tarif etmek yerine kendine olumsuz atıfta bulunmuştur.

Lester: Ben yokmuşum gibi davranmanızdan bıktım artık. Sizler her zaman istediğiniz gibi davranıyorsunuz, oysa ben sesimi bile çıkartmıyorum. Bir daha bana ne yapıp ne yapmayacağımı söylemeye kalkmayin. 66. $D k$.

Söylem Analizi (4): Rasyonalizm yaklaşımına göre değerlendirildiğinde Lester akılcı bir söz kullanmamıştır. Çünkü içine attığı birçok şeyi yıllar sonra bir akşam yemeğinde öfkeyle eşine ve kızına dile getirmesi, tabağı duvara firlatması mantıklı değildir. Yıllarca dışlanmaya yol açabilecek davranışlarda bulunmak ve dışlanmayı görmezden gelerek yaşamak yerine ADDT'nin savunduğu gibi hissedilen rahatsız edici durumları gerçekçi bir şekilde değerlendirip bunların düzeltilmesi için akılcı yöntemler bulabilirdi. Pasif bir direniş gösterip aile bireyleri arasındaki uyumun büyük yara almasında etkin rol almak yerine, zamanında önlemler alarak aile içinde sağlıklı bir iletişim ortamının oluşmasına yardımcı olabilirdi.

Lester: Karım beni aldatıyor ama benim umurumda değil. Evliliğimiz sadece formalite gereği. Ekonomik birliktelik. Etrafa mutlu bir imaj sergilemek için. 100. Dk. 
Söylem Analizi (5): Beklentilerinin karşılanmaması nedeniyle Carolyn'nin, eşi Lester'den uzaklaşması ve Lester'in değersizlik duygularıyla baş başa kalması, kendilerini zorunlu bir evliliğin içinde bulmalarına sebep olmuştur. Mantıklı bir şekilde yaklaşıldığında uzun yıllar birbirlerinden nefret etme noktasına gelmiş bu kişilerin daha sağlıklı bir hayat sürmeleri için boşanmayı tercih etmeleri beklenirdi. Fakat çevre faktörünün devreye girmesiyle içinde bulundukları kültürün de desteklediği birtakım kişisel çıkarlar sebebiyle bu ilişkinin devam ettiği görülmektedir. ADDT ve BT'ye göre kişilerin inanç ve düşünce sistemlerinin oluşumu çocukluk yıllarından itibaren toplum, aile, okul, kitap, sinema, televizyon vb. yollarla sağlanmaktadır. Amerikan toplumunda da bireyciliğin desteklendiği göz önünde bulundurulduğunda (Kağıtçıbaşı, 2005) bu toplumda yetişen Lester'in aldatma olayını ciddiye almamas1, Amerikan kültüründe önce bireyin ardından toplumun önemsenmesiyle ilintili olabilir. Dolayısıyla Lester başkalarına göre aldatma olayını değerlendirme yolunu seçmeden, kişisel çıkarlarına odaklanmıştır ve olayı görmezden gelmiştir. Fakat Lester, örneğin toplumculuk fikrinin ön planda olduğu Türk kültürü (Kağıtçıbaşı, 2005) içinde yetişseydi farklı inanç sistemi geliştirmiş olabileceğinden eşine yaklaşımı farklılık gösterebilirdi. Söylemlerden yola çıkılarak yapılan analizlerin ardından aşağıda Lester' in bazı davranışlarına göre yapılan analizlere yer verilmiştir.

Davranış analizi (1): ADDT'ye göre değerlendirildiğinde, 42 yaşında ve evli olan Lester'in, kızının yakın arkadaşı Angela'ya âşı olması, kızının yanında bu duygularını bastırmaya çalışmadan belli etmesi, sürekli onun hayaliyle yaşayıp mastürbasyon yapması, Angela ile cinsellik yaşama isteğiyle hayatını değiştirip mücadele etmesi ve ailesini daha da fazla ihmal etmesi nedeniyle aşırı derecede hedonist olduğu söylenebilir. Cinsel arzusu uğruna canlanabilmeyi başarabilen Lester, ergenlik dönemindeki kızının ihtiyaçlarını karşılamak için bir çaba sarf etmemiştir. Ailesinin dağılmasına seyirci kalıp, aynı zamanda Angela'nın da yaşını, yaşayabileceği duygusal sıkıntıları düşünmeyip sadece kendine odaklanması, ADDT'nin desteklediği sorumlu hedonizm ilkesine uymamaktadır.

Davranış analizi (2): 105. Dk. Lester cinsel amacına ulaşacağı noktada Angela'nın daha önce cinsellik yaşamadığını öğrenir ve şefkatli bir yaklaşımla ona dokunmaktan vazgeçer. Ancak, kendinden yaşça küçük, duygusal ve bedensel olgunluğa tam olarak erişememiş Angela'yı cinsel obje olarak görmemesinde etkili olan faktör (daha önce cinsellik yaşamaması) ADDT'ye göre değerlendirildiğinde Lester'in akılcı olmayan inancı olduğunun göstergesidir. Birçok toplumda da bekâretin kutsanması ve bekâretini koruyan kadınların mükâfatlandırılması gerektiği inancı (Berktay, 2000) toplumların akllcı olmayan inançlarına örnektir.

Karakter 2 - Carolyn Burnham: Hırslı bir emlak satıcısı olan Carolyn yarattı̆̆ mükemmeliyetçi dünyada yaşamaktadır. Kişisel bakımına çok özen gösteren, bahçeye bile çıkarken havalı terlikler giyen, akşam yemeklerinde kendi istediği müziği dinleten ve çevreye karşı mutlu bir aile tablosu sergilemek için çabalayan biridir. Eşi Lester'i küçümseyen Carolyn, gözünde yücelttiği emlak şirketlerinin lideri konumunda olan Buddy'e âşık olmuş ve eşini onunla aldatmıştır. Carolyn'in akılcı olmayan/mantık dış1 davranışlarının sebepleri bazı davranışlarından ve söylemlerinden yola çıkılarak analiz edilmeye çalışılmıştır.

Carolyn: Ben bugün bu evi satacağım. Satacağım. Bunu yapmalıyım. 11. Dk.

Söylem Analizi (6): Carolyn bu sözü hırslı bir şekilde söylemiş ve satacağı evi düzene sokmak için büyük çaba harcamıştır. BT'de yer alan mantıksız düşüncelerden, zorunluluğu ifade eden meli-malı cümlelerile kendini motive etmeye çalışmış fakat isteğine ulaşamayınca ağlama krizine girmiş ve kendini tokatlamıştır. ADDT'nin $A B C$ modeline göre değerlendirildiğinde, (A) evi satamaması, (C) ağlama krizine girmesi, kendini tokatlaması ve kendini aşağılamasıdır. (C)'nin oluşmasında etkili olan (B) ise akılcı olmayan, 'Bunu yapmalıyım.' inancıdır. Başarısızlığa uğradığında aşağıdaki sözleri kendine sarf etmiştir.

Carolyn: Sus! Ağlama. Kapa çeneni. Seni zayıf, güçsüz, aciz bebek... Sus! 14. Dk.

Söylem Analizi (7): Bu söylemde BT’ye göre bilişsel üçlüden, kendini değersizleştirme ve bilişsel hatalardan (mantıksız düşünce) etiketleme görülmektedir. Carolyn esnek olmadığı için kendine olumsuz 
etiketler (zayıf, güçsüz, aciz bebek) yapıştırmıştır. Aynı zamanda gerçekleştiremediği bir beklenti karşısında bunu büyük bir başarısızlık olarak görmesi aşırı genelleme örneğidir. ADDT'ye göre değerlendirildiğinde ise, mantıklı bireyler hayatın bir gül bahçesi olmadığını bildiklerinden olumsuzlukların da yaşanacağını bilerek üzücü olaylar karşısında büyük yıkımlar yaşamazlar. Oysa Carolyn, Ellis'in ileri sürdüğü üç temel akılcı olmayan inançtan biri olan, 'İyisini yapmalıyım ve tüm başarılarım takdir edilmeli, aksi halde başarısız biri olacağım.' inancı nedeniyle olumsuz değerlendirme yapıp kendini suçlamıştır. Bu suçluluğun temelinde ise kendini kabul etmemesi yatmaktadir.

Carolyn: Seninle gurur duyuyorum. Hareketlerine çok dikkat ettim. Bir kere bile hata yapmadın. 18 . $D k$.

Söylem Analizi (8): Bir basketbol maçında, kızı Jane'nin de içinde yer aldığı amigo kızların gösterisinden sonra gerçekleşen sohbette, Carolyn bu sözleri kızına söylemiştir. Bu sözlerde Carolyn'in gösteriyi zevkle izlemek yerine kızının hata yapıp yapmadığına odaklandığı görülmektedir. Jane'nin hiç hata yapmaması karşısında büyük sevinç yaşaması ADDT'ye göre değerlendirildiğinde Carolyn'in esnek olmayan mükemmeliyetçi yapısıyla ilgilidir.

Carolyn: Senden fena halde hoşlanıyorum. Senin şirketin emlak şirketlerinin kralı durumunda. Senin özel satış rekorun da çok etkileyici. Bazen senin yanında dururken beynini alıp kendi kafama koymak istiyorum. Aslında olaya teorik açıdan baktığımızda ben sana rakip sayılırım ama ben bile kendimi rakip olarak görmüyorum. 33. $D k$.

Söylem Analizi (9): Bir partide Buddy'le karşılaşan Carolyn bu sözlerle ona olan aşırı hayranlığını ve ilgisini dile getirmiştir. Fakat bunu yaparken BT'de yer alan mantıksız düşüncelerden aşırı büyütme ya da küçültmeyi kullanmıştır. Buddy’i abartılı bir şekilde yüceltirken kendini küçültmüştür. Bu durumun oluşmasına neden olan durum, BT'ye göre bilişsel üçlüden kendini değersizleştirmesi; ADDT'ye göre ise kendini kabul etmemesidir. Hedeflediği mükemmel kişiliğe ulaşmak için çaba sarf etmek yerine var olan potansiyelleri ışığında hareket edebilseydi hem kendini bu şekilde küçük görmezdi hem de Buddy'i ilahlaştırmazd1.

Carolyn: Hayatta kendinden başka kimseye güvenilmiyormuş. Acı ama gerçek. 69. Dk.

Söylem Analizi (10): Eşiyle yaşadıkları bir tartışmanın ardından kızı Jane'e söylemiş olduğu bu sözlerde BT'nin depresyon modelinden bilişsel üçlü'nün çevreyi değersizleştirme ve bilişsel hatalardan aşırı genelleme ve felaketleştirme vardır. Eşine güvenmemesiyle beraber güvensizliği tüm insanlara genellemesi akılcı olmayan bir yaklaşımdır. Yaşanan tartışmayı büyük bir trajedi haline getirerek hataları fark etmemeye çalışması da akılcı olmayan bir şekilde davrandığının göstergesidir. Aynı zamanda ikinci cümle, ADDT’nin oluşumunda etkisi bulunan Rasyonalizm yaklaşımı açısından değerlendirildiğinde, bilimsel bir dayanaktan uzaktır. Aşağıda Lester ve Caroly'nin bir diyaloğu analiz edilmiştir.76. $D k$.

Carolyn: Koltuğun üstüne bira döküp onu kirleteceksin.

Lester: Ne olacak? Bu sadece bir koltuk.

Carolyn: İtalyan ipek kaplamalı, tam 40.000 dolarlık koltuk. Normal bir koltuk değil.

Lester: Bence normal bir koltuk. Hayat böyle olmamalı. Bunların hepsi birer eşya ve bu eşyalar da senin için her şeyden önemli. Bu bir hastalık.

Söylem Analizi (11): Lester, Carolyn ile yalnız olduğu bir zamanda ona romantik sözler eşliğinde dokunmaya başlar. Her şey yolunda giderken Carolyn'in birayı fark etmesiyle bu diyalog gerçekleşir. ADDT'nin ABC modeline göre değerlendirildiğinde (A) Caroly'nin, eşinin birayı dökeceği korkusuyla onu uyarması, $(\mathrm{C})$ bedensel yakınlaşmayı sonlandırmaları, tartışmaları ve sonra Carolyn' in ortamı terk 
etmesidir. (C)'nin oluşmasında etkili olan her ikisinin farklı inançlarının (B) olmasıdır. (C)'nin oluşmasında tetikleyici olan Caroly'in akılcı olmayan inancıdır. Bu inanç (B), 'bu koltuk pahalı ve kirletilmemeli' şeklindedir. Lester'in diyalogdaki ilk inancı (B), 'hayat böyle olmamalı' inancıdır. Lester'in 'hayat böyle olmamalı' cümlesi şeklen meli-malı cümlelere örnek teşkil etse de diyalogun tamamı ele alındığında eşinin oluşturmuş olduğu sağlıksız ortama getirilen sağlıklı bir tepkidir. Çünkü bu cümlede, Lester'in yıllarca eşine ses çıkarmadan onun kuralları doğrultusunda yaşamasına rağmen birikmiş olan öfkesinin dişavurumu görülmektedir. Sağlkklı bir değişimin gerçekleşebilmesi için önce kişinin gerçeklerle yüzleşip farkındalığının artması gerekli olduğundan bu cümleyle farkındalığın artmaya başladığı söylenebilir. Lester'in diyalogdaki 2. inancı (B) ise, 'ne olursa olsun eşya eşyadır, o beni değil ben onu kullanırım' şeklindedir. Bu da akılcı bir inançtır.

BT'ye göre değerlendirildiğinde Carolyn, Lester'in ilişkilerini güçlendirmeye yönelik attığı adıma karşılık olumluyu geçersiz kılmak bilişsel çarpıtmasını kullanmıştır. Bilişsel çarpıtmalar, sorumlu tutmaya ve suçlamaya neden olabildiğinden eşler arasındaki iletişimi azaltmakta ve çifti boşanmaya götürebilmektedir (Christensen ve Shenk, 1991). Aşağıda Carolyn'in bir davranışı analiz edilmişsir.

Davranış analizi (3): Carolyn sevgilisi Buddy tarafından terk edilince büyük bir yıkım yaşar. 69. $D k$. İntihar edeceği sırada radyo programında söylenen hırslı ifadeler ('Bir kurban olmayı reddediyorum, sizin hayat felsefeniz bu olmalı.') kendisini etkiler ve intihar etmekten vazgeçer. 103. $D k$.

Daha önce de ifade edildiği gibi ADDT açıklıktan, esnekliktan ve alternatif aramaktan yanadır. Dolayısıyla Carolyn'in yaşadığı olayı travmatik hale getirmesi akılcı değildir. BT'ye göre değerlendirildiğinde ise Caroly'nin yaşadığı problemlerin aralıksız süreceğine inanması nedeniyle intiharı düşünmesi, bilişsel üçlü’nün geleceği değersizleştirme kavramına örnektir. Aynı zamanda mantıksız düşüncelerden felaketleştirme görülmektedir. Radyoda söylenenlerin Carolyn üzerinde büyük bir etkisinin olması ise, kitle iletişim araçlarının bireysel-toplumsal inançların ve düşüncelerin şekillenmesinde etkililiğinin göstergesidir. Programda kullanılan aşırı ben merkezci ifadeler Amerikan kültürünü yansıtmaktadır. Carolyn'in kendine/benine çok fazla odaklanmasının sebeplerinden biri de böyle bir kültürden beslenmesidir.

Karakter 3 - Jane Burnham: Ergenlik dönemi içinde çalkantılı günler yaşayan Jane kendini çirkin bulan ve özellikle gögüslerinin büyüklügünü takıntı haline getiren 16 yaşında bir gençtir. Bu takıntı sebebiyle bir an önce estetik ameliyatı olmak istemiştir. Anne ve babasını 'aptallar've 'uzaylılar'olarak etiketleyen Jane, hem anne-babasıyla hem kişiler arası iletişim çatışmaları yaşar. Fiziksel ve duygusal şiddetin olduğu bir aile ortamında yaşayan komşuları Ricky Fitts (Albay Frank Fitts'in oğlu) ile sevgilidir.

Davranış analizi (4): BT'ye göre değerlendirildiğinde, bilişsel üçlü'den çevreyi değersizleştirme ve mantıksız düşüncelerden etiketleme (aptallar, uzaylılar); ADDT'ye göre ise diğerlerini Kabul etmeme görülmektedir.Tüm bunların oluşmasında, hem ergenlik döneminde olmasının hem ebeveynlerinin Jane'ye karşı sorumluluklarını sağlıklı bir şekilde yerine getirmek yerine kendi hayatlarına odaklanmaları etkili olmuştur. Filmin giriş sahnesinde Jane'in söylediği aşağıdaki sözler bu yargıyı desteklemektedir.

Jane: Bana örnek olan bir baba istiyorum. Sınıf arkadaşlarımı eve getirdiğimde arka odada mastürbasyon yapan baba istemiyorum. Tam bir aptal. Keşke biri onu benim yanımdan uzaklaştırsa. 1 . $D k$.

Davranış analizi (5): Jane BT'de yer alan mantıksız düşüncelerden zihinsel filtreyi ve etiketlemeyi kullanmıştır. Güzel bir kız olmasına rağmen sadece göğüsleriyle uğraşması (zihinsel filtre örneği), kendine 'çirkin' etiketini yapıştırması akılcı/mantıklı davranmadığının göstergesidir. ADDT ve BT’ye göre akılcı olmayan inançların ya da mantık dışı düşüncelerin oluşumunda çevrenin rolü büyüktür. $\mathrm{Bu}$ nedenle, Jane'nin kendini çirkin bulmasında çok güzel olan, sürekli iddialı konuşan, Jane'yi küçümsediğini hissettiren, babasının aşık olduğu arkadaşı Angela'nın etkisi vardır.

Karakter 4 - Albay Frank Fitts: Burnham ailesinin komşusu olan emekli albay Frank, homofobik ve sinirli bir yapıya sahiptir. Eşine ve oğluna karşı uzak, buyurgan ve kontrolcüdür. Oğlu Ricky’i esrardan uzak tutmak ve disipline etmek için aşırı derecede kontrol eder. Tesadüfen pencereden Lester Burnham ve Ricky'nin hareketlerini görüp ilişki yaşadıkları yanılgısına kapılan Frank büyük bir öfkeye kapılır ve 
oğlunu döver. Tartışmadan sonra duygusal bir yıkım yaşayan Frank, Lester'in yanına gider, ona zarar verecek pozisyonda görülürken bir anda Lester'e sarılır ve dokunmaya başlar ancak karşıllk bulamaz. $\mathrm{Bu}$ hareketiyle eşcinsellere yönelik yoğun öfkesinin aslında hemcinslerine karşı ilgisini bastırmaya yönelik bir kamuflaj olduğu görülür. Albay Frank'ın akılcı olmayan davranışlarının sebepleri sarf ettiği bazı cümlelerden yola çıkılarak analiz edilmiştir.

Frank: Bu ülke cehennemin dibine doğru gidiyor. 25. $D k$.

Söylem Analizi (12): Frank bu cümleyi gazete okurken oğluna söylemiştir. ADDT'ye göre insanların mutlu olmaları ve eğlenceli yaşamaları için kendilerini, başkalarını (diğerlerini) ve dünyayı kabul etmeleri gerekir fakat Frank'ın BT'de yer alan felaketleştirmeyi de kullanarak ülkesini kabul etmediği görülmektedir. Bu cümle, BT'de yer alan bilişsel üçlünün çevreyi değerlensizleş̧tirmeyle de ilişkilidir. Sonuç olarak, bireylerde olduğu gibi ülkelerde de olumlu ve olumsuz durumlar görülebilir. Dolayısıyla, bir ülkede yaşanılan olumsuz durumları mantıklı bir şekilde değerlendirip neler yapılabileceğine veya gelecekte neler yaşanabileceğine yönelik gerçekçi yaklaşımda bulunmak yerine 'cehennem' metaforunu kullanarak ülkenin gidişatını değerlendirmesi Rasyonalizm yaklaşımına da aykırıdır.

Frank: Bu eşcinseller nasıl bu kadar utanmaz olabiliyorlar, utanmalılar. 26. Dk.

Frank: Karş1lık versene, yumuşak mısın sen? 72. $D k$.

Frank: Arkama yaslanıp oğlumun bir eşcinsel olmasına rahat gözle bakacağımı mı zannediyorsun? 94. $D k$.

Frank: Bir erkekle birlikte olacağıma ölürüm daha iyi. 95. $D k$.

Söylem Analizi (13): Frank, ilk cümleyi oğlu Ricky’le arabada konuşurken; ikinci cümleyi, eşyalarını izinsiz karıştırdığı gerekçesiyle oğlunu döverken; üçüncü ve dördüncü sözleri ise Rick’nin Lester'le sevgili olduğunu zannetmesiyle yine oğlunu döverken söylemiştir. Bu sözlerle birlikte Frank'ın homofobik olduğu görülmektedir. Bu sözlerde BT'de yer alan mantıksız düşüncelerden etiketleme (utanmaz, yumuşak) ve meli-malı cümleler (utanmalılar) kullanılmıştır. BT'ye göre bazı güdüler toplum tarafından bastırılması gereken ve kontrol edilemeyen mantıkdışı güdüler olarak kabul edilir. Böyle bir alg1 çocukluk döneminden itibaren oluşturulmaya başlandığı için değiştirilmesi de çok zordur. Dolayısıyla homofobi örneğinde olduğu gibi toplumun beklentileriyle ters düşme korkusu Frank'nn kendini kabul etmemesine (ADDT'nin kendini olduğu gibi kabul ilkesine aykırı) ve kendine sahte bir dünya (evlilikle beraber) yaratmasına sebep olmuştur. Kendi gerçeğiyle yüzleşmemek için abartılı erkeksi tavırlar sergileyip eşcinsellerle ilgili abartılı olumsuz ifadeler kullanmıştır. Frank'ın BT'de yer alan çaresizlik ve sevilemezlik temel inançlarına sahip olması nedeniyle mantık dışı yollara başvurduğu düşünülebilir.

Frank: Seni senin iyiliğin için dövdüm. İnsanların özel eşyalarına ve haklarına karşı saygı duymalisin.73. $D k$.

Söylem Analizi (14): Bu cümle ABC modeline göre değerlendirildiğinde (A) Ricky'nin, babasının dolabını karıştırması, (C) Frank'ın Ricky'i dövmesidir. (C)'ye sebep olan (B) ise Frank'ın Ricky'i saygılı biri olması ve onun iyiliği için gerekirse cezalandırabileceğine dönük akılcı olmayan inancıdır. BT'ye göre değerlendirildiğinde ise bağırarak söylenen ikinci cümle meli-malı cümlelere örnektir.

\section{Tartışma, Sonuç ve Öneriler}

Amerikan Güzeli filminin ana karakterleri Lester Burnham, Carolyn Burnham, Jane Burnham ve Albay Frank Fitts'in genel davranışları ve önemli görülen söylemlerinin ADDT ve BT'nin bazı kavram ve görüşleri açısından incelendiği çalışmadan elde edilen veriler ışı̆̆ında, karakterlerin hepsinde akılcı olmayan/mantıksız inanç sistemleri, düşünceler ve davranışlar görülmüştür. Bu durum bireysel, toplumsal ve aile yaşantılarının olumsuz etkilenmesine sebep olmuştur. ADDT'ye göre değerlendirildiğinde Lester, kendini kabul etmemiş, y1llarca durağanliğa karşı gelme eğilimi göstermemiş, sorumlu hedonizm ilkesine uygun davranmamış, ön planda olduğu düşünülen 'yaşama 
koşullarım iyi ve rahat olmal, böylece istediğim her şeyi çok fazla çaba sarf etmeden ve rahatsılılk duymadan elde edebilmeliyim, aksi takdirde bu lanet bir dünyadir ve hayat yaşamaya değmez' akılc1 olmayan inancıyla mantıksız davranışlar sergilemiştir. BT'ye göre ise, Lester'de bilişsel üçlü'den kendini değersizleştirme görülmekte olup ön plana çıkan bilişsel çarpıtmalar/mantıksız düşünceleri etiketleme ve felaketleştirmedir. Carolyn ADDT'ye göre, kendini ve çevresini kabul etmemiş, esnek olmayan mükemmelliyetçi tutumlarıyla hayatı kendine ve aile bireylerine çekilmez kılmış, sorumlu hedonizm ilkesine uygun davranmamış, 'iyisini yapmalıyım ve tüm başarılarım takdir edilmeli, aksi halde başarısız birisi olacăgım' akılcı olmayan inancıyla mantıksız davranışlar sergilemiştir. BT’ye göre ise Carolyn'de kendini, çevreyi ve geleceği değersizleştirme bilişsel üçlü'sü görülmekte olup ön plana çıkan bilişsel çarpıtmaları aşırı genelleme, etiketleme, meli-malı cümleler, olumluyu geçersiz kılmak, aşırı büyütme ya da küçültme ve felaketleştirmedir. ADDT'ye göre Jane, kendini ve çevresini kabul etmemiştir. BT'ye göre ise Jane'de bilişsel üçlü'den kendini ve çevreyi değersizleştirme görülmekte olup ön plana çıkan bilişsel çarpıtmaları etiketleme ve zihinsel filtredir. Son olarak Frank'ın bazı söylem ve davranışları ADDT'ye göre değerlendirildiğinde; Frank'ın homofobik, aşırı kuralcı, katı ve sinirli yapısının açıklık, esneklik ve alternatif aramaktan yana olan ADDT'ye uygun olmadığı; kendini, diğerlerini ve dünyayl kabul etmediği söylenebilir. Tüm bunların etkisiyle ADDT'nin oluşumunda etkisi olan Rasyonalizm yaklaşımına uygun düşmeyen davranışlar sergilemiştir. BT'ye göre ise Frank'ın davranışlarında bilişsel üçlü'den çevreyi değersizleştirme görülmekte olup ön plana çıan bilişsel çarpıtmaları etiketleme, felaketleştirme ve meli-malı cümledir. Frank'ın sevilemezlik ve çaresizlik temel inançlarına da sahip olduğu düşünülebilir. Her iki ekol açısından bakıldığında, tüm karakterlerin mantıksızlığa yatkınlıkları aile bireyleri, arkadaşları, kitle iletişim araçları ve içinde yaşadıkları toplum tarafından beslenmiştir. Ancak Ellis'in (1994) de vurguladığı gibi insanların mantıksızlığa yatkınlıkları olduğu gibi yaratma ve kendini gerçekleştirme potansiyelleri de vardır (Clark, 2000). Dolayısıyla insanların mantıksızlığa yatkınlıklarının önüne geçmeye çalışıp pozitif yönlerini güçlendirmek gerekmektedir. Nitekim Amerikan Güzeli filminde de görüldüğü gibi, mantık dışı inançlar ve düşünceler sadece bireylerin değil ailelerin de, o ailelerin oluşturduğu toplumların da yıkıc1 (görünürde fark edilmese de) bir kimlik geliştirmesine yol açmaktadır. Duygusal ve davranışsal sorunların ortadan kaldırılması için terapötik süreçte ADDT danışanlara akılcı olmayan inançların nasıl olumsuz sonuçlar ortaya çıkardığını göstererek danışanların kendilerini, diğerlerini ve dünyayı koşulsuz kabul etmelerine (Ellis, 2004); BT ise danışanların kendi düşünce yapılarını tanımalarına, gözlemlemelerine ve takip etmelerine yardımcı olmaktadır (O'Donohue ve Fisher, 2009). Bu bağlamda, ruh sağlığ alanında eğitim alan ve çalışan bireylere her iki ekolün kuramsal öneminin fark ettirilmesinin; derinlemesine bir anlatımının yapılmasının; mantıksız inanç, düşünce ve davranışların nasıl ortaya çıktığının somut bir şekilde gösterilmesinin ve çözüm yolları sunmak amacıyla bu çalışmada olduğu gibi film analizi yönteminin kullanılmasının faydalı olacağı düşünülmektedir. Bu ekollerin ruh sağlı̆̆1 alanında taşıdıkları büyük önemle birlikte film analizi yöntemi de önem teşkil etmektedir. Çünkü senaristlerin, yapımcıların ve yönetmenlerin filmler aracılığıyla insanlara ulaştırmak istedikleri mesajlar mevcuttur. Bu mesajlar yoluyla insanların fenomenolojik dünyalarına girebilmektedirler. Örneğin, bir yönetmen modern dünyanın insanları giderek yalnızlaştırdığını düşünüyorsa insanların bu durumu fark edip sorgulamaları ve harekete geçmeleri için bir film çekebilmektedir. Özellikle sinema filmlerinin unutulmayan sahneleri, karakterleri ve replikleri insanlar üzerinde oldukça etkili olmaktadır. Amerikan Güzeli filminin büyük bir yankı uyandırmasının sebebi de mutluluk getirdiği düşünülen modern dünya dayatmalarının insanları derin bir yalnızlığa ve akılcı olmayan yollara sürüklediği gerçeğini çarpıcı karakterleri ve sahneleriyle ortaya koymasıdır. Amerikan Güzeli filminin karakterlerinin günlük hayatttan yola çıkılarak oluşturulduğu düşünüldüğünde, bu karakterlerin günümüzde karş1lıları azımsanmayacak kadar fazladır. Yalnızlık, anlamsızlık, yalıtılmışlık, çaresizlik, sevilemezlik, yabancılaşma hissi yaşayanların sayısı giderek artmaktadır. Bu durum filmde de görüldüğü gibi bireylerin ve toplumların akılcı olmayan inanç, düşünce ve davranışlarının artmasına yol açmaktadır. Bunun gibi, içinde yaşadığımız fakat farkına varmakta zorlandığımız birçok durum önemli yönetmenler ve senaristler tarafından sinema aracılığıyla insanlara sunulmaktadır. Dolayısıyla insanların gerçek dünyalarına, kimlik arayışlarına, anlamsızlığa, yabancılaşmaya, ruhsal sorunlara dokunan Sam Mendes, Pedro Almodovar, Nuri Bilge Ceylan, Çağan Irmak, Zeki Demirkubuz, Ferzan Özpetek, Woody Allen, Kim Ki Duk gibi yönetmenlerin filmlerinin farklı ekoller bağlamında psikolojik analizlerinin yapılmasının da alana önemli katkılar sağlayacağı düşünülmektedir. Bu nedenle yapılan bu çalışmanın eğitimcilere, ruh sağlığı eğitimi alanlara ve alan çalışanlarına yol göstereceği düşünülmektedir. 
Amerikan Güzeli fillminde ADDT ve BT’nin tüm kavram ve görüşleriyle açıklanabilecek sahneler olmaması nedeniyle her iki ekolün ancak bazı kavram ve görüşleriyle karakterlerin söylem ve davranış analizlerinin yapılması bu çalışmanın sınırlılığıdır.

\section{Kaynaklar}

Acar, T. ve Voltan-Acar, N. (2013). 'Babam ve Oğlum' filminin çok kuşakl1/kuşaklararas1 aile terapisinin temel kavramları açısından değerlendirilmesi. Kuram ve Uygulamada Eğitim Bilimleri, 13(1), 37-53.

Arkar, H. (1992). Beck'in depresyon modeli ve bilişsel terapisi. Dü̈sünen Adam: Psikiyatri ve Nörolojik Bilimler Dergisi, 5(1-3), 37-40.

Arnkoff, D. B. ve Glass, C. R. (1992). Cognitive therapy and psychotherapyintegration. D. K. Freedheim (Yay. haz.). History of Psychotherapy: A Century of Change içinde (ss. 657-694). Washington, DC: APA.

Basic, M. M. (1992). Reading the alcoholic film: Analysis of 'The Country Girl'. The Sociological Quarterly, 33(2), 211-227.

Beck, A., T. (2001). Bilişsel Terapi temel ilkeler ve ötesi, (Ş. Hisli, Çev). Ankara: Türk Psikologlar Derneği.

Beck, A. T. (2006). Bilişsel terapi ve duygusal bozukluklar. A. Türkcan (Çev.). İstanbul: Litera.

Beck, A. T., Rush, A. J., Shaw, B. F. ve Emery, G. (1987). Cognitive therapy of depression. New York: The Guilford Press.

Berg-Cross, L., Jennings, P. ve Baruch, R. (1990).Cinematherapy: Theory and application. Psychotherapyin Private Practice, 8(1), 135-156.

Berktay, F. (2000). Tek tanrılı dinler karşısında kadın. İstanbul: Metis.

Boyacı, M. ve İlhan, T. (2016). Bilişsel davranışçı terapi yaklaşımının film analizi yöntemiyle incelenmesi. Mersin Üniversitesi Eğitim Fakültesi Dergisi, 12(2), 734-746. doi: 10.17860/efd.03838

Bozdağ, Y. (2018). Film analizi yöntemi ile aile terapileri: Gilbert'in Hayalleri. Yaşam Becerileri Psikoloji Dergisi, 2(3), 87-95.

Burns, D. (2008). İyi hissetmek. Karaosmanoğlu, H. A. (Çev. Ed.). İstanbul: Psikonet.

Cag, P. ve Voltan-Acar, N. (2015). A view of the symbolic-experiantal family therapy of Carl Whitaker through movie analysis. Educational Sciences: Theory and Practice, 15(3), 575-586. doi: 10.12738/estp.2015.3.2477

Christensen, A. J. ve Shenk, L. (1991). Communication, conflict, and psychological distance in nondisstressed, clinic, divorcing couples. Journal of Consulting and Clinical Psychology, 39(3), 458-463.

Clark, L. (2000). SOS Duygulara Yardım. (G.Yazgan, Çev). İstanbul: Evrim Yayınları.

Corey, G. (2008). Psikolojik danışma, psikoterapi kuram ve uygulamaları. (A. Sağlam, Çev). Ankara: Mentis.

Dobson, K. S. ve Block, L. (1988). Historical and philosophical bases of the cognitive-behavioral therapies. K. S. Dobson (Yay. haz.), Handbook of Cognitive-Behavioral Therapies içinde (ss. 3-38). New York: Guilford Press.

Ellis, A. ve Harper, R. A. (2005). Akılcı yaşam klavuzu kitabı. (S. Kunt-Akbaş, Çev). Ankara: HYB.

Ersanl1, K. (2012). Davranışlarımız: Gelişim ve ögrenme. Samsun: Eser.

Goodson, I. ve Walker, R. (1988). Putting life into educational research. R. R. Sherman ve R. B.Webb (Yay. haz.). Qualitative Research in Education: Focus and Methods, içinde (ss. 108-122). London: Routledge.

Gramaglia, C., Jona, A., Imperatori, F., Torre, E. ve Zeppegno, P. (2013). Cinema in the training of psychiatry residents: Focus on helping relationships. BMC Medical Education, 13(90), 1-6. doi: $10.1186 / 1472-6920-13-90$

Hackney, H. ve Cormier, S. (2008). Psikolojik danışma ilke ve teknikleri: Psiklojik yardım süreci el kitabl, (T. Ergene, ve S. Aydemir Sevim, Çev). Ankara: HYB.

Hewison, D. (2003). 'Oh Rose, thou art sick!' Anti-individuation forces in the film American Beauty. Journal of Analytical Psychology, 48, 683-704.

Kağıtçıbaşı, Ç. (2005). Yeni insan ve insanlar. İstanbul: Evrim Kitap. 
Kağnıcı, D. Y. (2015). Psikolojik danışman eğitiminde cinsel yönelim olgusunun irdelenmesi: Benim Çocuğum filmi. Türk Psikolojik Danışma ve Rehberlik Dergisi, 5(44), 83-95.

Klemenc-Ketis, Z. ve Kersnic, J. (2011). Using movies to teach professionalism to medical students. BMC Medical Education, 11(60). doi:10.1186/1472-6920-11-60

Köroğlu, E. (2008). Düşünsel duygulanımcı davranıs terapisi. Ankara: HYB.

Mangot, A. G. ve Murthy, V. S. (2017). Cinema: A multimodal and integrative medium for education and therapy. Ann Indian Psychiatry, 1(51).

Marcus, E. R. (1999). Empathy, humanism, and the professionalism of medical education. Academic Medicine, 74(11), 1211-1215. doi: 10.1097/00001888-199911000-00014

Mert, A. ve Soyer, B. (2014). 'Kevin Hakkında Konuşmalıyız' filminin Bowlby'nin çocukluk dönemi bağlanma stilleri ve Minuchin' in yapısal aile sistemleri yaklaşımı temel kavramları kullanılarak değerlendirilmesi. OPUS - Türkiye Sosyal Politika ve Çalışma Hayatı Araştırmaları Dergisi, 4(7), 100-115.

Morsünbül, Ü. (2015). Bal, Süt ve Yumurta filmlerinin Ericson'un psikososyal gelişim kuramı açısından analizi. Ilköğretim Online, 14(1), 181-187. doi: 10.17051/io.2015.5113

Nelson-Jones, R. (1982). Danışma psikolojisi kuramları kitabı. Akkoyun, F. (Yay. haz.). Ankara: 72TDFO Ltd.Şti.

O'Donohue, W. T. ve Fisher, J. E. (2009). General principles and empirically supported techniques of cognitive behavior therapy. John Wiley \& Sons.

Peoples, K. ve Helsel, S. (2013). Bridging the gap between theory and practice with film: How to use Fight Club to teach existential counseling theory and techniques. Education and General Studies, 1(2), 1-7, doi: 10.1177/2158244013497028

Preminger, S. (2012). Transformative art: Art as means for long term neurocognitive change. Frontier in Human Neuroscience, 6(96). doi: 10.3389/fnhum.2012.00096

Quadrelli, S., Colt, H. G. ve Semeniuk, G. (2009). Appreciation of the aesthetic: A new dimension for a medicine and movies program. Family Medicine, 41(5), 316-318.

Richards, R. (2016). Önsöz. D. Wedding ve R. M. Niemiec (Yay. haz.), Sinema ve Akıl Sağlı̆g içinde (ss. 7-11). İstanbul: Kaknüs.

Sanchez, J. C., Gutierrez, J. C. ve Morales, M. D. (2010). Cinema and theater as training tools for health students. Family Medicine, 42(6), 398-399.

Sharf, S. R. (2000). Theories of psychotherapy and counseling: Concepts and cases. USA: Brooks/ Cole.

Şenol-Durak, E. ve Fışıloğlu, H., (2007). Film analizi yöntemi ile Virginia Satir aile terapisi yaklaşımına bir bakış. Türk Psikoloji Yazıları, 10(20), 43-62.

Türküler-Aka, B. ve Gençöz, F., (2010). Sinematerapinin mükemmeliyetçilik ve mükemmeliyetçilikle ilgili şemalar üzerindeki etkisi. Türk Psikoloji Dergisi, 25(65), 69-77.

Ülker-Tümlü, G. ve Voltan-Acar, N. (2014). 'Issız Adam' filminin gerçeklik terapisine dayalı incelenmesi. Insan\&Insan, 2, 62-73.

Wedding, D. ve Niemiec, R. M. (2016). Sinema ve akıl să̆lı̆̆ı. (R. Arvay Aratan, Çev.). İstanbul: Kaknüs.

Weishaar, M. E. (1993). Aaron T. Beck. London: Sage.

Yıldırım, A. ve Şimşek, H. (2008). Sosyal bilimlerde nitel araştırma yöntemleri. Ankara: Seçkin.

\section{Extended Abstract}

\section{Introduction}

Social, anthropological and cultural knowledge about people at different times and environments is acquired through the art of cinema. Cinema is used as a tool also in the mental health education. Cinema, when used as a therapeutic intervention tool, movies contain useful behaviours are given as homework with which clients can gain insight about their problems and they can develop positive rules in their lives or client's thoughts and feelings about the film are examined after watching together. Thus, it will help the clients to develop long-term empathy. Cinema is not only for the development of the clients and society but also individuals in the psychology trainingto increase knowledge about psychological health and illness and are used for the development of therapeutic skills. This study aimed to analyze American Beauty film with the basic concepts of Albert Elis's Rational Emotive Behavioral Therapy (REBT) and Aaron Beck's Cognitive Therapy (CT) scholls and so to strengthen the theoretical 
knowledge of students who receive mental health education and field workers. In line with this priority, REBT's and CT's basic concepts explained and then film characters' important behaviours and discourses were examined in terms of these conceps.

\section{Method}

This study is a descriptive study that analyzed the film American Beauty in terms of REBT and CT's basic concepts. One of the qualitative research methods document analyses were used in the study. Document analysis covers the analysis of writing sources and visual sources such as film, video, picture that contain information about targeted case or cases (Yıldırım \& Şimşek, 2008). The main characters of American Beauty film Lester Burnham (father), Carolyn Burnham (mother), Jane Burnham (child) and Colonel Fitts's (neighbor) general behaviors and seen important cues were analyzed in terms of REBT and CT's basic concepts.

\section{Result and Discussion}

In the light of the data obtained via the study in terms of some concepts and and views of REBT and CT analyses of general behaviors and important discourses of American Beauty movie's main characters, Lester Burnham, Carolyn Burnham, Jane Burnham and Colonel Frank Fitts, it has seen that all characters have illogical belief systems, thoughts and behaviours. This situation negatively affected both individual and family experiences. When evaluated according to REBT, Lester did not accept himself, did not show any tendency to stand against stagnation for years, did not act in accordance with the principle of responsible hedonism, acted irrationally with his forefronted irrational belief of "living conditions must be good and comfortable, so that I can get everything I want without effort or discomfort, otherwise, this is a damned world and life is not worth living". According to CT, Lester devaluated himself and his cognitive distortions/illogical thoughts were catastrophizing and labelling. According to REBT, Carolyn did not accept herself and the others, with her unflexible perfectionist attitudes she made life difficult to herself and family members did not act in accordance with the principle of responsible hedonism and she acted illogical behaviours with her irrational beliefs.According to CT, Carolyn devalued herselft, surrounding and future. Cognitive distortions/illogical thoughs of Caroline were over-generallization, labelling, should statements, disqualifying the pozitive, magnification or minimization and catastrophizing. According to REBT, Jane did not accept herself and the others. According to CT, Jane devalued herself and the environment from the cognitive triad, and the prominent cognitive distortions were labeling and mental filter. Finally, when evaluated some of the discourses and behaviors according to the REBT, his homophobic, overly prescriptive, rigid and irritable structure is not suitable for REBT which supports clarity, flexibility and alternative search; he did not accept himself, others, and the world, and under the influence of all of these, he exhibited behaviors that did not conform to the approach of Rationalism, which had an impact on the formation of REBT. According to CT, Frank devalued environment and his cognitive distortions were labelling, should statements and catastrophizing. It is thought that Frank has basic beliefs which are unlovability and inevitability. With respect to both schools, tendency of illogicallity of all characters was fed by family members, friends, society where they live and mass communication. This situation caused breake up of both their lives and family without aware of all characters.

In order to notice the theoretical importance of both schools to individuals who are educated and working in the field of mental health and to make a detailed expression, as in this study, it is thought to provide contributions to field that using the movie analysis method and doing psychological analyses of films focusing on people's real worlds, identity searches, meaninglessness, alienation, and psychological problems. 